\title{
Effects of Achyranthes bidentata alcohol on proliferation capacity of osteoblasts and miRNA in Runx2
}

\author{
SHAN HUA $^{1}$ and XUEXUE ZHANG ${ }^{2}$ \\ ${ }^{1}$ Medical College of Nanchang University, Nanchang, Jiangxi 330031; \\ ${ }^{2}$ Department of Pain Management, The First Affiliated Hospital of Nanchang University, \\ Nanchang, Jiangxi 330006, P.R. China
}

Received December 4, 2018; Accepted April 16, 2019

DOI: 10.3892/etm.2019.7723

\begin{abstract}
Achyranthes bidentata is a herbal plant commonly used in the treatment of osteoporosis and bone nonunion with traditional Chinese medicine. Achyranthes bidentata alcohol is a major component extracted from Achyranthes bidentata, which has been proved to be able to exert a variety of pharmacological effects, such as anti-inflammation, antipyresis, anti-rheumatism, diuresis and anti-osteoporosis. Thirty male Sprague-Dawley rats aged 4 weeks were used in the experiment. All primary rat osteoblasts were cultured and amplified for further experiments. The osteoblasts were divided into six groups (5 rats in each group): the culture medium control group, the $25 \mu \mathrm{g} / \mathrm{ml}$ achyranthol group, the $50 \mu \mathrm{g} / \mathrm{ml}$ achyranthol group, the $100 \mu \mathrm{g} / \mathrm{ml}$ achyranthol group, $200 \mu \mathrm{g} / \mathrm{ml}$ achyranthol group, and the $25 \mu \mathrm{M}$ PD $98059+200 \mu \mathrm{g} / \mathrm{ml}$ achyranthol group. In this study, the effect of Achyranthes bidentata alcohol on the proliferation of osteoblasts was detected via methyl thiazolyl tetrazolium (MTT) assay. The effect of Achyranthes bidentata alcohol on the alkaline phosphatase (ALP) activity in osteoblasts was analyzed via ALP assay. The effect of Achyranthes bidentata alcohol on the expression of osteoblast marker gene, Runt-related transcription factor 2 (Runx2), was detected via reverse transcription-quantitative polymerase chain reaction (RT-qPCR) and immunohistochemistry. Moreover, the phosphorylation or activation of extracellular signal-regulated kinase (ERK) in osteoblasts induced by Achyranthes bidentata alcohol was analyzed using western blotting. Achyranthes bidentata alcohol increased cell proliferation in a dose-dependent manner, increased the micro ribonucleic acid (miRNA) level in Runx2, enhanced the ALP activity in osteoblasts, and stimulated the activation
\end{abstract}

Correspondence to: Dr Xuexue Zhang, Department of Pain Management, The First Affiliated Hospital of Nanchang University, 17 Yongwai Zhengjie Street, Donghu, Nanchang, Jiangxi 330006, P.R. China

E-mail:vvr4704@163.com

Key words: Achyranthes bidentata, osteoblasts, proliferation, Runx2, ERK of ERK $(\mathrm{P}<0.05)$. The expression of Runx 2 with the inhibitor PD98059 was decreased significantly compared with that in the Achyranthes bidentata alcohol group $(\mathrm{P}<0.01)$. Immunohistochemical results manifested that the percentage of Runx 2 positive cells in treated tissues was obviously higher than that in untreated tissues $(\mathrm{P}<0.01)$. Therefore, Achyranthes bidentata alcohol promotes the proliferation capacity of osteoblasts in a dose-dependent manner, enhances the expression of miRNA in Runx2, and stimulates the osteogenic differentiation of osteoblasts through activating the ERK signal transduction pathway.

\section{Introduction}

Osteoporosis is a serious health problem, and there are no fully effective treatment methods. The loss of activity of osteoblasts or the increase of activity of osteoclasts leads to osteoporosis (1). However, inhibiting the osteoclast-mediated reabsorption alone cannot reduce the severity of bone, joint or muscle pain (2). Drugs promoting proliferation or inducing differentiation of osteoblasts play an important role in bone formation (3). In some studies, agents that stimulate bone formation have been used in the treatment of osteoporosis, such as growth hormone (4). Due to relevant side effects, however, the expected improvement in bone mass and bone-binding rate has not been confirmed (5). Therefore, it is necessary to continue to search new and effective remedial measures for bone loss in the elderly.

In history, Chinese herbal medicinal plants in folk medicine are often used for the discovery and development of new medicines. Achyranthes bidentata, an upright annual herb of Amaranthaceae, is distributed in the hilly areas of China, South Korea, Japan and India, which, in traditional and folk medicine in these and other adjacent countries, is widely described as having anti-inflammatory, anti-pyretic, anti-rheumatic and diuretic activities (6). In ancient times, in fact, Achyranthes bidentata was recommended for prolonging the life span, and it was believed that it could strengthen muscles and bones, improve hepatic and renal tension and promote blood flow (7).

The pharmacological activity and active chemical components of the whole-plant Achyranthes bidentata, especially Achyranthes bidentata root, have been widely 
studied. Its major component, Achyranthes bidentata alcohol, possesses anti-asthmatic, anti-inflammatory, anti-pyretic, anti-rheumatic and diuretic activity $(8,9)$. Wattel et al revealed that the osteoclast differentiation declines due to quercetin (10). It is reported that another kind of chemical substance in the plant, ketosteroid, can prevent bone loss in ovariectomized animals $(8,9)$. The main bioactive component of oleanane-type Achyranthes bidentata alcohol has been proved to have various activities, such as anti-fertility $(11,12)$, antitumor (13), analgesia, anti-inflammation and promotion of blood circulation (14). Achyranthes bidentata alcohol can effectively prevent and treat retinoic acid-induced osteoporosis in rats (15-17). However, the mechanism of osteogenic effect of Achyranthes bidentata alcohol on bone mesenchymal stem cells (BMSCs) has not been fully clarified.

Mitogen-activated protein kinase (MAPK) plays a key role in regulating the signal transduction pathways of embryogenesis, differentiation, proliferation and death of living cells, in which extracellular signal-regulated kinase (ERK) has been proved to be an important signaling molecule involved in the differentiation of the precursor adipose cell line 3T3-L1 into mature adipose cells $(18,19)$. MAPK is considered to be able to mediate the activation of several gene products involved in bone formation, including alkaline phosphatase (ALP) and several transcription factors, such as Runt-related transcription factor 2 (Runx2), Osx and BMB2 (20).

The transcription factor Runx 2 is a major decisive factor of osteoblast differentiation, whose expression is prior to osteoblast differentiation. The inactivation of Runx 2 prevents osteoblast differentiation, and the haploid insufficiency of Runx 2 leads to skeletal dysplasia, namely cranial dysplasia characterized by delaying osteoblast differentiation, and leading to clavicle and open fontanelle dysplasia. However, little is still known about several biological aspects of Runx2. For example, the nature of molecular events leading to the accumulation of Runx2 in osteoblasts is unknown to a large extent. It is necessary to study whether and how Runx 2 promotes bone formation through differentiated osteoblasts (21).

In this study, whether Achyranthes bidentata alcohol enhances osteoblast proliferation and osteogenic effect through activating ERK1/2 signaling pathway was investigated. The effect of Achyranthes bidentata alcohol on the proliferation of osteoblasts was detected via methyl thiazolyl tetrazolium (MTT) assay. The ALP activity was measured to detect the effect of Achyranthes bidentata alcohol on cell differentiation. Moreover, the micro ribonucleic acid (miRNA) expression level in the transcription factor Runx 2 of the bone formation marker was detected via reverse transcription-quantitative polymerase chain reaction (RT-qPCR).

\section{Materials and methods}

Main experimental materials. Dexamethasone, ascorbic acid, $\beta$-sodium glycerophosphate and inhibitor PD98059, MTT (both from Sigma-Aldrich; Merck KGaA), microtiter plate reader (Bio-Tek Instruments, Inc.), ALP activity assay kit (Nanjing Jiancheng Bioengineering Institute), Bio-Rad protein assay reagent (Bio-Rad Laboratories, Inc.), chemiluminescence detection system (Cell Signaling Technology) and image analysis system (NIH Image, version 1.61).
Preparation of primary osteoblasts in rats. Thirty male Sprague-Dawley rats aged 4 weeks (100-120 g) were purchased from the Laboratory Animal Science of Nanchang University, and placed under controlled environment in cage $\left[22^{\circ} \mathrm{C}, 60 \%\right.$ humidity, 12 -h light/dark cycle (from 6:00 to $18: 00 /$ from $18: 00$ to $6: 00)$ ] with free access to food and water. Briefly, the femur and tibia were dissected, the end of bone was cut off, and the bone marrow was rinsed with $2 \mathrm{ml}$ ice-cold $\alpha$-MEM containing $10 \%$ (v/v) fetal bovine serum (FBS). The bone marrow was repeatedly sucked, blown and beaten to obtain the osteoblast suspension. Cells were counted using a hemocytometer, and inoculated in a $25 \mathrm{ml}$ cell culture flask with $\alpha$-MEM containing $10 \% \mathrm{FBS}$ at a density of $1 \times 10^{6}$ cells $/ \mathrm{ml}$, followed by culture in an incubator with $5 \% \mathrm{CO}_{2}$ at $37^{\circ} \mathrm{C}$. After 3 days, non-adherent cells were washed and removed using phosphate-buffered saline (PBS) 2-3 times, and adherent cells were further cultured in the $\alpha$-MEM until $90 \%$ cells were fused. Bone mesenchymal stem cells (BMSCs) were cultured and amplified for further experiments.

The study was approved by the Ethics Committee of the First Affiliated Hospital of Nanchang University (Nanchang, China).

Cell culture and treatment. Osteoblasts were cultured in the osteogenic induction medium (OIM) supplemented with $10 \%$ FBS, $0.1 \mu \mathrm{M}$ dexamethasone, $50 \mu \mathrm{M}$ ascorbic acid and $10 \mathrm{mM} \beta$-sodium glycerophosphate. The stock solution of Achyranthes bidentata alcohol was prepared in PBS (pH 7.2-7.4), filtered using a $0.22 \mu \mathrm{M}$ filter, and added to the cell culture until the final concentration was 25, 50, 100 and $200 \mu \mathrm{g} / \mathrm{ml}$. The inhibitor PD98059 at a final concentration of $25 \mu \mathrm{M}$ was added into the medium with Achyranthes bidentata alcohol.

MTT assay. The cell viability was detected via MTT assay at 1, 2, 3, 4, 5, 6 and 7 days after treatment with 25, 50, 100 and $200 \mu \mathrm{g} / \mathrm{ml}$ Achyranthes bidentata alcohol. MTT was dissolved in the medium containing 10\% FBS and filtered using the $0.2 \mu \mathrm{m}$ filter. The medium was replaced with MTT solution $(200 \mu \mathrm{l} /$ well $)$ for cell incubation at $37^{\circ} \mathrm{C}$ for $4 \mathrm{~h}$. Purple formazan was dissoved with dimethyl sulfoxide. At the end of incubation, the MTT solution was removed and $150 \mu 110 \%$ sodium lauryl sulfate in $0.01 \mathrm{M} \mathrm{HCl}$ was added into each well. The absorbance was measured at $570 \mathrm{~nm}$ on a plate reader using $630 \mathrm{~nm}$ filter membrane as a reference.

Determination of ALP activity. ALP in cells was detected at 1, 3,7 and 14 days after culture using the commercial kit. The cell culture medium was discarded, cells were scraped and lysed in $10 \mathrm{mM}$ Tris- $\mathrm{HCl}(\mathrm{pH} 7.5)$ containing $0.1 \%$ Triton $\mathrm{X}-100$, followed by ultrasonic treatment. The ALP activity was determined in the lysate according to the manufacturer's instructions. Absorbance of the final product in ALP reaction was measured at $520 \mathrm{~nm}$ using a microtiter plate reader. Four repeated results in each group were analyzed, the total protein was detected using the Bradford's method, and the enzyme activity was standardized.

$R T$ - $q P C R$. The total RNA was isolated from bone marrow stromal cells using RIPA lysis buffer (Takara), and reverse transcribed into the first-strand complementary 
deoxyribonucleic acid (cDNA) with AccessQuick ${ }^{\mathrm{TM}}$ RT-PCR kit (cat. no. A1701; Promega). Mixtures were prepared in the PCR tube: Dntp Mixture (10 Mm) $1 \mu \mathrm{l}$, Oligo Dt Primer $(2.5 \mu \mathrm{M}) 1 \mu \mathrm{l}$, RNA $5 \mu \mathrm{l}$, then add Rnase Free dH2O to $10 \mu \mathrm{l}$. The reaction of denaturation and annealing was carried out at $65^{\circ} \mathrm{C}$ for $5 \mathrm{~min}$ and on ice for $5 \mathrm{~min}$. Then, the above denatured and annealed reaction liquid was mixed with $5 \mathrm{X}$ PrimeScript TM Buffer, $4 \mu \mathrm{l}$; Rnase Inhibitor (40 U/ $\mu \mathrm{l}), 0.5 \mu \mathrm{l}$; PrimeScript TM Rtase, $0.5 \mu \mathrm{l}$; Rnase Free $\mathrm{dH} 2 \mathrm{O} 5 \mu \mathrm{l}$, a total of $20 \mu \mathrm{l}$, and reacted at $42^{\circ} \mathrm{C}$ for $30 \mathrm{~min}$, then at $95^{\circ} \mathrm{C}$ for $5 \mathrm{~min}$. Then the template DNA was used for the TaqMan PCR (Thermo Fisher Scientific, Inc.) of Runx2. Glyceraldehyde 3-phosphate dehydrogenase (GAPDH) was used as an internal reference gene. After 2\% agarose gel electrophoresis, the product of RT-qPCR was developed with ethidium bromide. The optical density (OD) was quantified using the gel image software with the $2^{-\Delta \Delta \mathrm{Cq}}$ method (22). Primer sequences for RT-qPCR are as follows: Runx-2, forward,5'-GCACCCAGCCCATAATAGA-3' and reverse, 5'-TTGGAGCAAGAGAA CCC-3'. GAPDH, forward, 5'-GGCACAGTCAAGGCTGAGA ATG-3' and reverse, 5'-ATGGTGGTGAAGACGCCAGTA-3'. It was synthesized at $50^{\circ} \mathrm{C}$ and amplified (40 cycles).

Western blotting. Cultures were collected at the specified time and extracted in Tris-buffered saline (50 mM Tris-HCl, $\mathrm{pH} 7.6$, $150 \mathrm{mM} \mathrm{NaCl}$ ) containing $1 \%$ Triton X-100, 1\% Nonidet P-40 and $0.5 \mathrm{mM}$ phenylmethylsulfonyl fluoride at $4^{\circ} \mathrm{C}$. After centrifugation at $12,000 \mathrm{x} \mathrm{g}$ and $4^{\circ} \mathrm{C}$ for $10 \mathrm{~min}$, the protein content in the supernatant was determined using the Bio-Rad protein assay reagent. An equal amount of protein lysate $(25 \mu \mathrm{g})$ was electrophoresed in the $10 \%$ sodium dodecyl sulfate-polyacrylamide gel, followed by membrane transfer to PVDF membrane and reaction with primary rabbit anti-rat p-ERK, ERK monoclonal antibodies (1:300; cat. nos. ab201015, ab184699; Abcam) and secondary goat anti-rabbit polyclonal antibody (1:600; cat. no. ab205718). Finally, the antigen-antibody complex was visualized using the chemiluminescence detection system. The protein band was quantitatively analyzed using the image analysis software (NIH).

Immunohistochemistry. The tissue was fixed with $10 \%$ formaldehyde at $20^{\circ} \mathrm{C}$ for $16 \mathrm{~h}$ Paraffin-embedded tibial tissue sections $(5 \mu \mathrm{m})$ were deparaffinized in xylene and rehydrated with gradient ethanol solution. In epitope retrieval, sections were routinely heated via microwave for $10 \mathrm{~min}$ in $0.01 \mathrm{M}$ citrate buffer ( $0.01 \mathrm{M}$ sodium citrate and $0.01 \mathrm{M}$ citric acid, $\mathrm{pH}$ 6.0). At room temperature $\left(22^{\circ} \mathrm{C}\right), 100 \mu 13 \% \mathrm{H}_{2} \mathrm{O}_{2}$ was added to sections to inhibit the activity of endogenous peroxidase for $10 \mathrm{~min}$. Then sections $(5 \mu \mathrm{m})$ were sealed with $5 \%$ normal goat serum at $23^{\circ} \mathrm{C}$ for $1 \mathrm{~h}$, and incubated with primary rabbit anti-rat Runx 2 monoclonal antibody (1:200; cat. no. 12556; Cell Signaling Technology) at $4^{\circ} \mathrm{C}$ overnight. PBS was added as the negative control. Finally, sections were washed at room temperature $\left(22^{\circ} \mathrm{C}\right)$ and incubated with the biotinylated goat anti-rabbit polyclonal antibody (1:400; cat no. 8885; Cell Signaling Technology) for $45 \mathrm{~min}$. After sections were washed with PBST 3 times and incubated at $23^{\circ} \mathrm{C}$ with $\mathrm{SABC}$ for $30 \mathrm{~min}$, staining was performed using $100 \mu \mathrm{l}$ pigment solution. The brown colour glass slide was counterstained with hematoxylin for $1 \mathrm{~min}$, followed by observation under an optical microscope (Olympus). The percentage of positive region or cells in each sample was calculated using Image-Pro Plus 5.0 software.

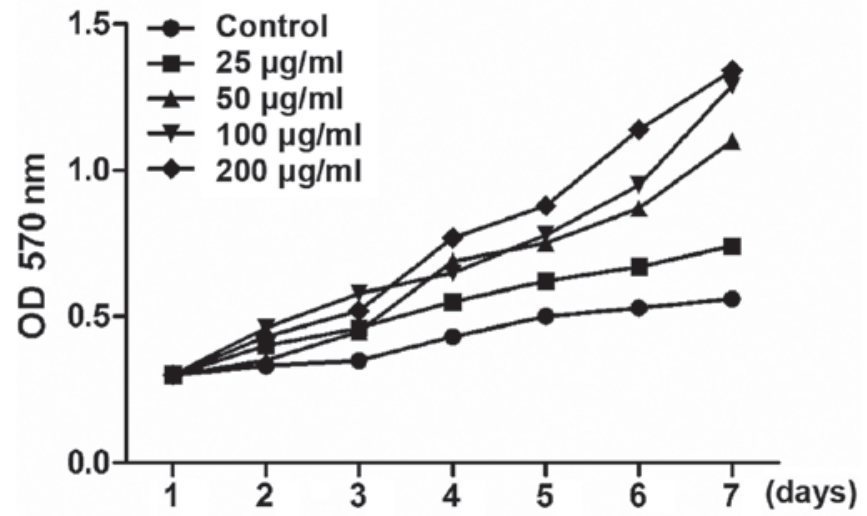

Figure 1. Effect of Achyranthes bidentata alcohol on proliferation of osteoblasts. Cells were cultured with blank vector or Achyranthes bidentata alcohol in different concentrations, and the absorbance was measured at 1,2, $3,4,5,6$ and 7 days after induction.

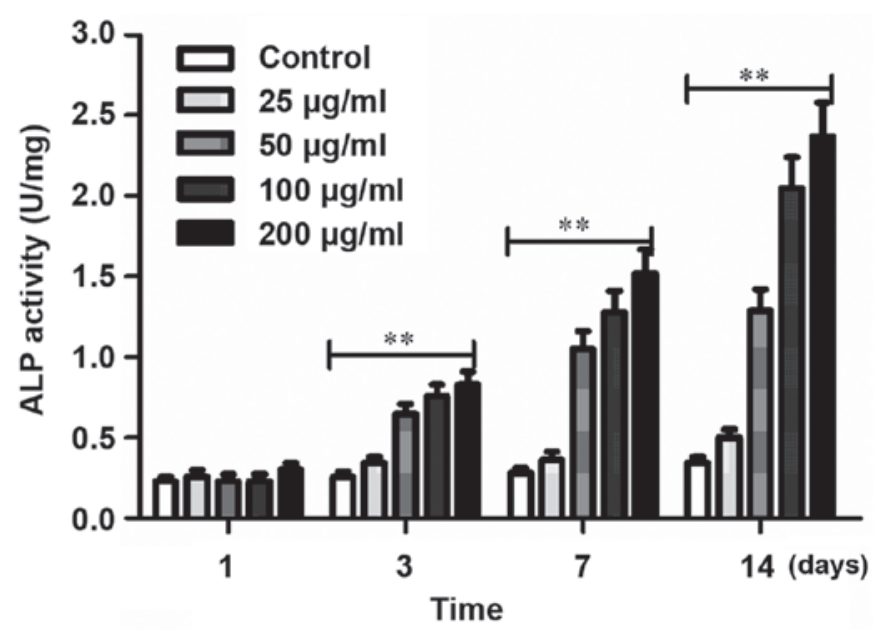

Figure 2. Determination of ALP activity in osteoblasts in each group at different time-points. ALP activity is significantly higher in cells in the Achyranthes bidentata alcohol group than that in the control group $\left({ }^{* *} \mathrm{P}<0.01\right)$. ALP, alkaline phosphatase.

Statistical analysis. Continuous variables are presented as mean \pm standard error of mean (SEM), and analyzed using Student's t-test. The proceude was repeated 6 times. All statistical analyses were performed using GraphPad Prism 5.0 (GraphPad Software, Inc.). $\mathrm{P}<0.05$ indicates that the difference was statistically significant.

\section{Results}

Effect of Achyranthes bidentata alcohol on proliferation of osteoblasts. The pro-proliferative effect of Achyranthes bidentata alcohol $(25,50,100$ and $200 \mu \mathrm{g} / \mathrm{ml})$ on osteoblasts was detected via MTT assay. Growth curves revealed that Achyranthes bidentata alcohol increased the cell proliferation in a dose-dependent manner (Fig. 1).

Effect of Achyranthes bidentata alcohol on ALP activity in osteoblasts. Achyranthes bidentata alcohol increased the ALP activity in cells in a dose-dependent manner, and the most significant was under $200 \mu \mathrm{g} / \mathrm{ml}$ (Fig. 2). 


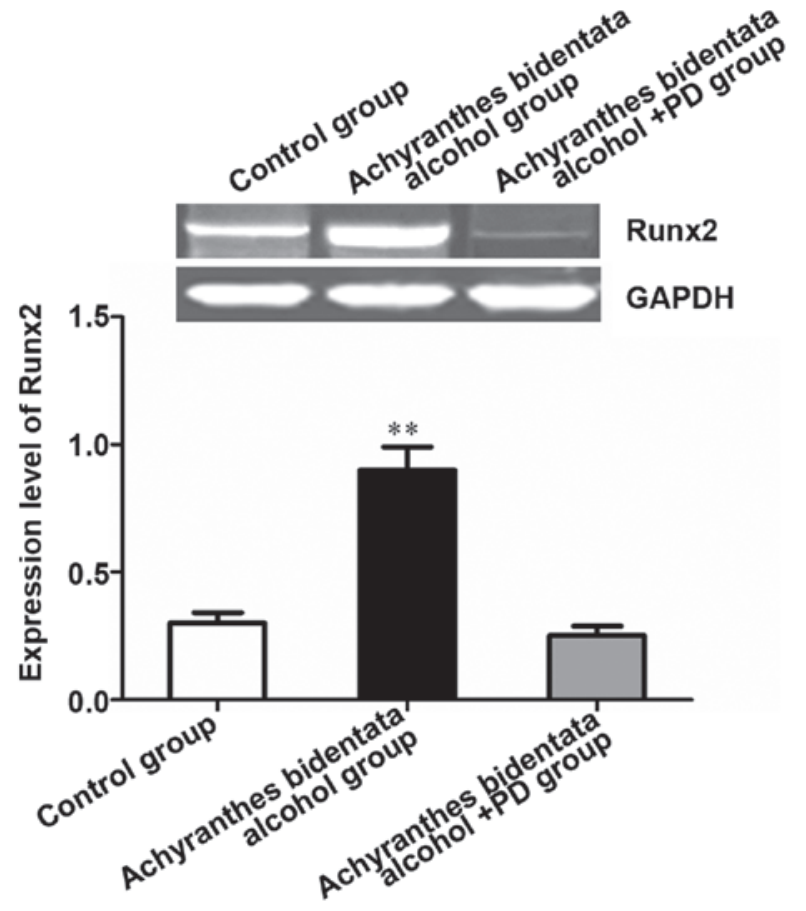

Figure 3. Achyranthes bidentata alcohol enhances the osteogenic effect of osteoblasts through the ERK signaling pathway. The effect of Achyranthes bidentata alcohol on the gene expression in osteoblasts was confirmed via RT-qPCR. ${ }^{* *} \mathrm{P}<0.01$, the difference was extremely significant. ERK, extracellular signal-regulated kinase.

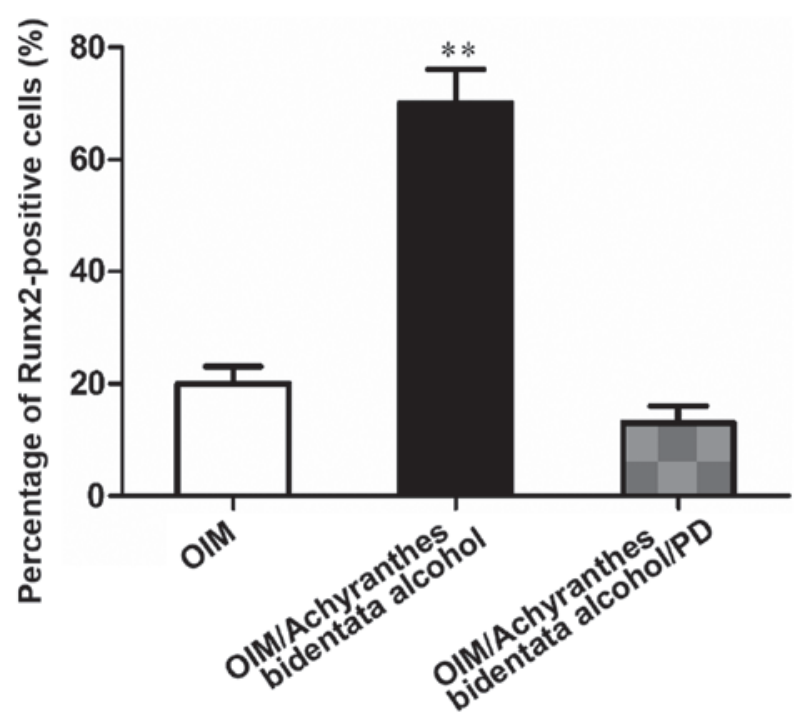

Figure 4. Percentage of Runx2-positive cells in the treated and untreated groups. ${ }^{* *} \mathrm{P}<0.01$. Runx2, Runt-related transcription factor 2 .

Effect of Achyranthes bidentata alcohol on the expression of osteoblast marker gene Runx2. Results of RT-qPCR showed that the expression of Runx 2 was significantly higher in Achyranthes bidentata alcohol group and nearly 3 times that in the control group $(\mathrm{P}<0.01)$. After treatment with the inhibitor PD98059, the expression of Runx2 was decreased significantly compared with that in the Achyranthes bidentata alcohol group $(\mathrm{P}<0.01)$, indicating that Achyranthes bidentata alcohol promotes the expression of osteoblast marker gene Runx2 (Fig. 3).
A
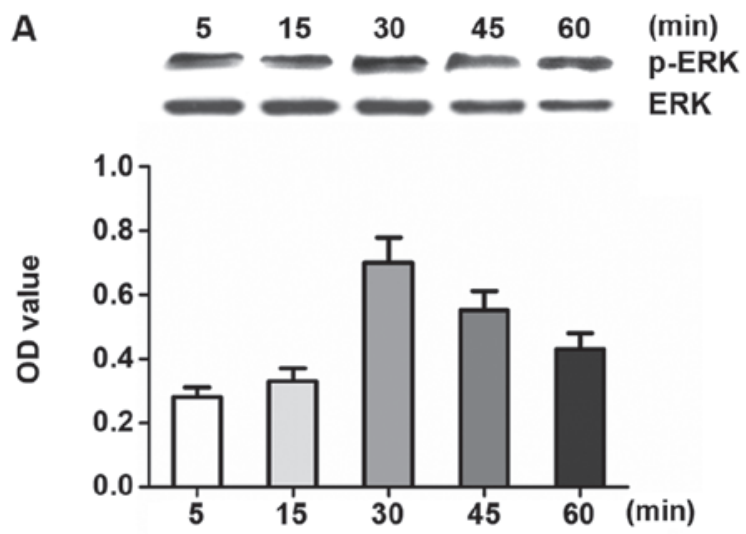

B

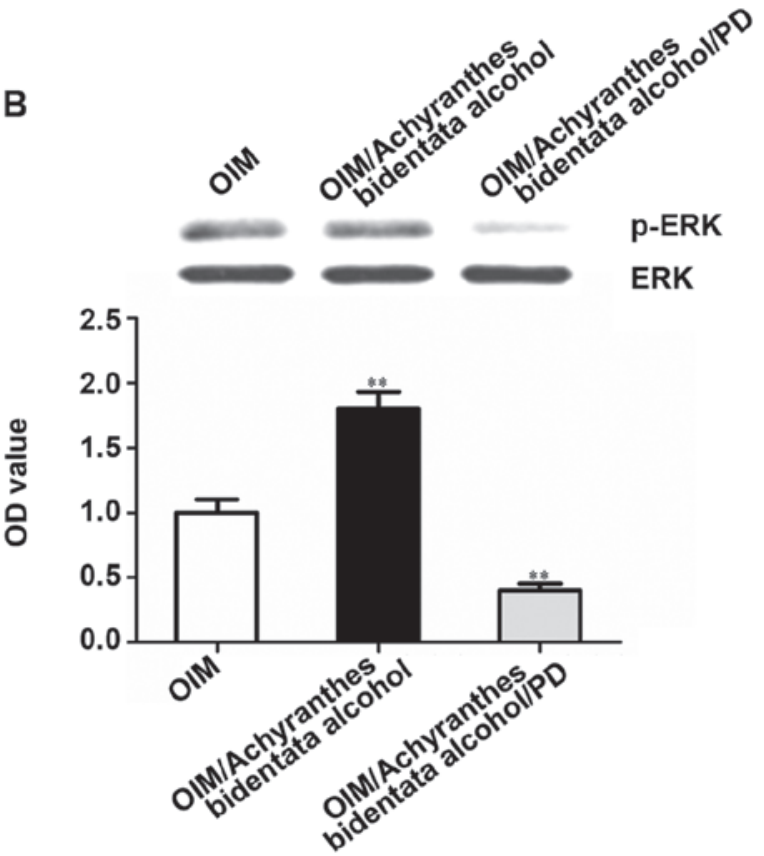

Figure 5. Achyranthes bidentata alcohol can induce ERK activation in osteoblasts. (A) After serum starvation for $24 \mathrm{~h}$, osteoblasts were treated for some time in serum-free OIM containing Achyranthes bidentata alcohol $(100 \mu \mathrm{g} / \mathrm{ml})$. Achyranthes bidentata alcohol enhanced ERK phosphorylation. The ERK phosphorylation began to decrease after 30 min and the ERK phosphorylation in 45 and 60 min was still stronger than that in $5 \mathrm{~min}$. (B) Before treatment with serum-free OIM, OIM with Achyranthes bidentata alcohol or OIM with Achyranthes bidentata alcohol (100 $\mu \mathrm{g} / \mathrm{ml})$, BMSCs were pretreated with $25 \mu \mathrm{M}$ PD98059 for $1 \mathrm{~h}$ and serum-starved for $24 \mathrm{~h}$. Western blotting was performed for lysates using p-ERK and total ERK antibodies. The optical density was quantified, and each band of p-ERK was normalized into the corresponding total ERK band. ${ }^{* *} \mathrm{P}<0.01$ vs. OIM group. ERK, extracellular signal-regulated kinase; OIM, osteogenic induction medium; BMSCs, bone mesenchymal stem cells.

Detection of percentage of Runx2-positive cells via immunohistochemistry. Immunohistochemical results manifested that the percentage of Runx2-positive cells in treated tissues was obviously higher than that in untreated tissues $(\mathrm{P}<0.01)$, further confirming the osteogenic effect of Achyranthes bidentata alcohol on osteoblasts (Fig. 4).

Achyranthes bidentata alcohol regulated osteoblast differentiation through activating ERK. It has been proved in previous studies that ERK is involved in regulating osteogenic differentiation in osteoblasts (18). However, the mechanism 
of Achyranthes bidentata alcohol-mediated ERK signal in regulating osteogenic differentiation remains unclear. In this study, following osteoblast growth and differentiation in the presence of Achyranthes bidentata alcohol with or without specific ERK inhibitor PD98059 $(25 \mu \mathrm{M})$, the expression of osteoblast marker gene in cells was analyzed. It was observed that the ERK inhibitor significantly reduced the Runx2 gene expression (Fig. 4).

Results of western blotting showed that Achyranthes bidentata alcohol enhanced ERK phosphorylation in osteoblasts grown under osteogenic induction. The ERK phosphorylation began to decrease after $30 \mathrm{~min}$ and the ERK phosphorylation in 45 and 60 min was still stronger than that in 5 min (Fig. 5A). Besides, Achyranthes bidentata alcohol-induced ERK phosphorylation in cells treated with PD98059 remarkably declined (Fig. 5B).

\section{Discussion}

The stimulatory effect of Achyranthes bidentata alcohol on osteoblast differentiation has been proved in previous studies $(15,16)$. Although Achyranthes bidentata alcohol is considered as a potential candidate for the treatment of osteoporosis, the mechanism of its osteogenic effect on BMSCs has not been fully studied yet. It was clearly demonstrated in this study that Achyranthes bidentata alcohol promoted osteogenesis of BMSCs and stimulated ALP. Upregulation of Runx2 mRNA transcripts indicated that they were regulated in Achyranthes bidentata alcohol-activated osteogenesis process. The enhanced ERK phosphorylation mediated by Achyranthes bidentata alcohol further revealed that the promoting effect of Achyranthes bidentata alcohol on osteogenesis involved the regulation of ERK signaling pathway.

Some studies have already found several proteins and transcription factors and their functions (21-24). Runx2 is considered to play a role as a major osteogenic transcription factor in the maturation process of osteoblasts (23). Osx, a novel zinc finger transcription factor, is specifically expressed in developing bones (25).

MAPK is a member of serine/threonine kinase family, which plays an important regulatory role in the gene transcription signal transduction in response to changes in cellular environment $(26,27)$. To further describe the regulatory mechanism of osteoblast differentiation mediated by Achyranthes bidentata alcohol, whether ERK phosphorylation in Achyranthes bidentata alcohol-treated cultures was affected was studied. Results of this study clearly revealed that p-ERK was upregulated rapidly and significantly in Achyranthes bidentata alcohol-treated cultures. Obviously, these results suggest that Achyranthes bidentata alcohol stimulates osteogenic differentiation in osteoblasts through activating ERK signal. However, whether Achyranthes bidentata alcohol-induced osteoblast differentiation involves the regulation of JNK and p38 has not been explored. To study the influence of JNK and p38 specific inhibitors SP600125 and SB203580 on osteogenesis, it is necessary to further clarify the mechanism and acting site of Achyranthes bidentata alcohol.

In conclusion, results in this study provide direct evidence proving that Achyranthes bidentata alcohol plays an important role in enhancing osteoblast differentiation, and stimulates the osteogenic differentiation of osteoblasts through activating the ERK signal transduction pathway. From the perspective of treatment, results in this study demonstrate that Achyranthes bidentata alcohol is an effective material for the prevention and treatment of osteoporosis. However, further work is needed to fully understand the role of Achyranthes bidentata alcohol in regulating osteogenesis.

\section{Acknowledgements}

Not applicable.

\section{Funding}

No funding was received.

\section{Availability of data and materials}

The datasets used and/or analyzed during the present study are available from the corresponding author on reasonable request.

\section{Authors' contributions}

SH wrote the manuscript. SH and XZ performed PCR and western blotting. XZ was responsible for immunohistochemistry. Both authors have read and approved the final manuscript.

\section{Ethics approval and consent to participate}

The study was approved by the Ethics Committee of the First Affiliated Hospital of Nanchang University (Nanchang, China).

\section{Patient consent for publication}

Not applicable.

\section{Competing interests}

The authors declare that they have no competing interests.

\section{References}

1. Niu Y, Li Y, Huang H, Kong X, Zhang R, Liu L, Sun Y, Wang T and Mei Q: Asperosaponin VI, a saponin component from Dipsacus asper wall, induces osteoblast differentiation through bone morphogenetic protein-2/p38 and extracellular signal-regulated kinase 1/2 pathway. Phytother Res 25: 1700-1706, 2011.

2. Licata AA: Discovery, clinical development, and therapeutic uses of bisphosphonates. Ann Pharmacother 39: 668-677, 2005.

3. Zhang P, Dai KR, Yan SG, Yan WQ, Zhang C, Chen DQ, $\mathrm{Xu} \mathrm{B}$ and $\mathrm{Xu} \mathrm{ZW}$ : Effects of naringin on the proliferation and osteogenic differentiation of human bone mesenchymal stem cell. Eur J Pharmacol 607: 1-5, 2009.

4. Berger I, Piecha G, Rabkin R, Kaya N, Geldyyev A, Sun D, Chen Y, Koleganova N and Gross ML: Growth hormone treatment prevents osteoporosis in uremic rats. Histol Histopathol 22: 1231-1239, 2007.

5. Lühe A, Künkele KP, Haiker M, Schad K, Zihlmann C, Bauss F, Suter L and Pfister T: Preclinical evidence for nitrogen-containing bisphosphonate inhibition of farnesyl diphosphate (FPP) synthase in the kidney: Implications for renal safety. Toxicol In Vitro 22: 899-909, 2008. 
6. Deng HB, Cui DP, Jiang JM, Feng YC, Cai NS and Li DD: Inhibiting effects of Achyranthes bidentata polysaccharide and Lycium barbarum polysaccharide on nonenzyme glycation in D-galactose induced mouse aging model. Biomed Environ Sci 16: 267-275, 2003.

7. Shen H, Yuan Y, Ding F, Liu J and Gu X: The protective effects of Achyranthes bidentata polypeptides against NMDA-induced cell apoptosis in cultured hippocampal neurons through differential modulation of NR2A- and NR2B-containing NMDA receptors. Brain Res Bull 77: 274-281, 2008.

8. Jin LQ, Zheng ZJ, Peng Y, Li WX, Chen XM and Lu JX: Opposite effects on tumor growth depending on dose of Achyranthes bidentata polysaccharides in C57BL/6 mice. Int Immunopharmacol 7: 568-577, 2007.

9. Li JX, Hareyama T, Tezuka Y, Zhang Y, Miyahara T and Kadota S: Five new oleanolic acid glycosides from Achyranthes bidentata with inhibitory activity on osteoclast formation. Planta Med 71: 673-679, 2005.

10. Wattel A, Kamel S, Prouillet C, Petit JP, Lorget F, Offord E and Brazier M: Flavonoid quercetin decreases osteoclastic differentiation induced by RANKL via a mechanism involving NF kappa B and AP-1. J Cell Biochem 92: 285-295, 2004.

11. Shibeshi W, Makonnen E, Zerihun L and Debella A: Effect of Achyranthes aspera $\mathrm{L}$. on fetal abortion, uterine and pituitary weights, serum lipids and hormones. Afr Health Sci 6: 108-112, 2006.

12. Chen XM, Xu YJ and Tian GY: Physical-chemical properties and structure elucidation of abPS isolated from the root of Achyranthes bidentata. Yao Xue Xue Bao 40: 32-35, 2005 (In Chinese).

13. Han SB, Lee CW, Yoon YD, Lee JH, Kang JS, Lee KH, Yoon WK, Lee K, Park SK and Kim HM: Prevention of arthritic inflammation using an oriental herbal combination BDX-1 isolated from Achyranthes bidentata and Atractylodes japonica. Arch Pharm Res 28: 902-908, 2005.

14. Zhou ZD and Xia DJ: Effect of Achyranthes bidentata polysaccharides stimulated dendritic cells co-cultured with cytokine induced killer cells against SW480 cells. Zhongguo Zhong Yao Za Zhi 38: 1056-1060, 2013 (In Chinese).

15. Zhang M, Wang Y, Zhang Q, Wang C, Zhang D, Wan JB and Yan C: UPLC/Q-TOF-MS-based metabolomics study of the anti-osteoporosis effects of Achyranthes bidentata polysaccharides in ovariectomized rats. Int J Biol Macromol 112: 433-441, 2018

16. Zhang R, Hu SJ, Li C, Zhang F, Gan HQ and Mei QB: Achyranthes bidentata root extract prevent OVX-induced osteoporosis in rats. J Ethnopharmacol 139: 12-18, 2012.

17. Pearson G, Robinson F, Beers Gibson T, Xu BE, Karandikar M, Berman K and Cobb MH: Mitogen-activated protein (MAP) kinase pathways: Regulation and physiological functions. Endocr Rev 22: 153-183, 2001.
18. Jaiswal RK, Jaiswal N, Bruder SP, Mbalaviele G, Marshak DR and Pittenger MF: Adult human mesenchymal stem cell differentiation to the osteogenic or adipogenic lineage is regulated by mitogen-activated protein kinase. J Biol Chem 275: 9645-9652, 2000 .

19. Sale EM, Atkinson PG and Sale GJ: Requirement of MAP kinase for differentiation of fibroblasts to adipocytes, for insulin activation of p90 S6 kinase and for insulin or serum stimulation of DNA synthesis. EMBO J 14: 674-684, 1995.

20. Alanay Y, Avaygan H, Camacho N, Utine GE, Boduroglu K, Aktas D, Alikasifoglu M, Tuncbilek E, Orhan D, Bakar FT, et al: Mutations in the gene encoding the RER protein FKBP65 cause autosomal-recessive osteogenesis imperfecta. Am J Hum Genet 86: 551-559, 2010

21. Wei J, Shimazu J, Makinistoglu MP, Maurizi A, Kajimura D, Zong H, Takarada T, Lezaki T, Pessin JE, Hinoi E, et al: Glucose uptake and Runx 2 synergize to orchestrate osteoblast differentiation and bone formation. Cell 161: 1576-1591, 2015.

22. Livak KJ and Schmittgen TD: Analysis of relative gene expression data using real-time quantitative PCR and the 2(-Delta Delta C(T)) method. Methods 25: 402-408, 2001.

23. Nishio Y, Dong Y, Paris M, O'Keefe RJ, Schwarz EM and Drissi H: Runx2-mediated regulation of the zinc finger Osterix/Sp7 gene. Gene 372: 62-70, 2006.

24. Komori T, Yagi H, Nomura S, Yamaguchi A, Sasaki K, Deguchi K, Shimizu Y, Bronson RT, Gao YH, Inada M, et al: Targeted disruption of Cbfal results in a complete lack of bone formation owing to maturational arrest of osteoblasts. Cell 89: 755-764, 1997.

25. Nakashima K, Zhou X, Kunkel G, Zhang Z, Deng JM, Behringer RR and de Crombrugghe $\mathrm{B}$ : The novel zinc finger-containing transcription factor osterix is required for osteoblast differentiation and bone formation. Cell 108: 17-29, 2002.

26. Lee MH, Kim YJ, Kim HJ, Park HD, Kang AR, Kyung HM, Sung JH, Wozney JM, Kim HJ and Ryoo HM: BMP-2-induced Runx 2 expression is mediated by Dlx 5 , and TGF-beta 1 opposes the BMP-2-induced osteoblast differentiation by suppression of Dlx5 expression. J Biol Chem 278: 34387-34394, 2003.

27. Turjanski AG, Vaqué JP and Gutkind JS: MAP kinases and the control of nuclear events. Oncogene 26: 3240-3253, 2007.

This work is licensed under a Creative Commons Attribution-NonCommercial-NoDerivatives 4.0 International (CC BY-NC-ND 4.0) License. 